\title{
Pesquisa-ação e mediação dialógica como práticas metodológicas para emergência da ação comunicativa em Conselhos Gestores de Políticas Públicas ${ }^{*}$
}

\author{
Carla Beatriz Marques Rocha e Mucci \\ Universidade Federal de Viçosa (UFV) / Programa de Pós-Graduação em Extensão Rural \\ Viçosa / MG - Brasil \\ Rennan Lanna Martins Mafra \\ Universidade Federal de Viçosa (UFV) / Departamento de Comunicação Social e \\ Programa de Pós-Graduação em Extensão Rural \\ Viçosa / MG - Brasil
}

\begin{abstract}
Este artigo objetiva examinar duas práticas metodológicas de suporte à participação nos espaços dos Conselhos Gestores de Políticas Públicas: a pesquisa-ação e a mediação dialógica. De modo mais específico, pretende-se refletir se e como tais práticas podem ser estimuladoras à emergência da ação comunicativa em meio aos desenhos institucionais participativos dos Conselhos. Para isso, foi feito um estudo no âmbito do Conselho Municipal de Desenvolvimento Rural Sustentável de Viçosa (MG) (CMDRS). A base teórica do artigo constitui-se pela discussão sobre legitimidade e participação no âmbito da democracia deliberativa, e a metodologia utilizada constitui-se por uma combinação entre pesquisa documental e pesquisa qualitativa. Como principais resultados, compreende-se que tais práticas metodológicas se constituem, a depender do modo como são utilizadas, como importantes mecanismos de qualificação dos espaços participativos formais.
\end{abstract}

DOI: http://dx.doi.org/10.1590/0034-7612136991

Artigo recebido em 27 jun. 2014 e aceito em 9 set. 2015.

${ }^{1}$ Este artigo é parte dos resultados do projeto de pesquisa "Fortalecimento Cívico e Aprimoramento da Participação de Comunidades Rurais junto ao Conselho Municipal de Desenvolvimento Rural Sustentável de Viçosa/MG", financiado pela Fundação de Amparo à Pesquisa do Estado de Minas Gerais (Fapemig) e pelo Ministério Público do Estado de Minas Gerais, como parte do "Programa Cidade e Alteridade: Convivência Multicultural e Justiça Urbana".

* Esse trabalho contou com bolsa de pesquisa financiada pela Coordenação de Aperfeiçoamento de Pessoal de Nível Superior (Capes). 
Palavras-chave: participação; democracia deliberativa; pesquisa-ação; mediação dialógica; conselhos.

Investigación-acción y mediación dialógica como práctica metodológica para emergencia de la acción comunicativa en los Consejos Gestores de la Política Pública

Este artículo examina dos prácticas metodológicas para apoyar la participación en los espacios de los Consejos Gestores de Políticas Públicas: la investigación-acción y la mediación dialógica. Más específicamente, tenemos la intención de examinar si y cómo estas prácticas pueden ser estimulantes de la emergencia de la acción comunicativa entre los diseños institucionales de participación de los Consejos. Para esto, se realizó un estudio en el Consejo Municipal de Desarrollo Rural Sustentable de Viçosa (MG) (CMDRS). La base teórica del artículo está en discusión de la legitimidad y la participación dentro de la democracia deliberativa y la metodología utilizada es por una combinación de trabajo de documentación e investigación cualitativa. Como principales resultados, se entiende que estas prácticas metodológicas constituyen, en función de cómo se utiliza, cómo los mecanismos de calificación importantes de espacios participativos formales.

Palabras-chave: participación; democracia deliberativa; investigación para la acción; mediación dialógica; consejos.

Research-action and dialogical mediation as methodological practices favoring the emergence of communication initiatives in Councils of Public Policy Managers

This article examines two methodological practices to support the participation in the spaces of Managers Councils of Public Policies: action research and dialogical mediation. More specifically, we intend to consider whether and how such practices may be stimulating the emergence of communicative action among the participatory institutional designs of the Councils. In order to do it, a study was done in the Municipal Council for Sustainable Rural Development of Viçosa - MG (CMDRS). The theoretical basis of the article is based on the discussion of legitimacy and participation within the deliberative democracy; the methodology used is based on a combination of documental and qualitative researches. As main results, it is understood that such methodological practices constitute, depending on how they are used, as important qualification mechanisms of formal participatory spaces.

KEYWORDs: participation; deliberative democracy; action research; dialogic mediation; councils.

\section{Introdução}

O tema proposto em discussão neste artigo visa estabelecer aproximações entre a noção de democracia deliberativa e os processos participativos que ocorrem no âmbito dos Conselhos Gestores de Políticas Públicas. Em meio a um amplo universo de possibilidades investigativas que tal tema sugere, a reflexão posta em debate pretende problematizar como é possível à ação comunicativa — inspirada na visada deliberacionista de autores como Habermas (1995), Cohen (1997), Dryzek (2004), Maia (2007) e Bohman (2000, 2009) — emergir nos complexos espaços participativos dos Conselhos Gestores. Tal emergência, na seara aberta pela democracia deliberativa, se mostra fundamental para qualificar os processos participativos, 
sobretudo sob o ponto de vista da legitimidade que eles podem ser capazes de imprimir às decisões, no contexto de uma gestão pública sensível a cenários sociais complexos e pluralistas. Para isso, pretende-se examinar duas práticas metodológicas de suporte à participação nos espaços dos Conselhos Gestores: a pesquisa-ação (Mafra, 2012) e a mediação dialógica (Ruas, 2006). O esforço aqui empreendido se volta, nesse sentido, a refletir se e como tais práticas podem ser estimuladoras à emergência da ação comunicativa, em meio aos desenhos institucionais participativos dos Conselhos Gestores de Políticas Públicas, tão amplamente disseminados na contemporânea experiência democrática brasileira.

O universo empírico que tornou possível a elaboração deste estudo se refere ao contexto do Conselho Municipal de Desenvolvimento Rural Sustentável de Viçosa (MG) (CMDRS). Criado desde o ano de 2004, o CMDRS é um órgão gestor vinculado ao poder público municipal, que possui caráter consultivo ou deliberativo - a depender da política pública nele posta em discussão - e que se institui enquanto espaço de gestão do desenvolvimento rural sustentável do município. O art. 1ํ da Lei no 1.592/2004, que institui o CMDRS, atribui caráter consultivo e deliberativo ao Conselho. Após reformulado pela Lei $\mathrm{n}^{\circ}$ 2.081/2010, ele foi alterado. De acordo com o art. 1ํㅗ $\S 1^{\circ}-$ O Conselho Municipal de Desenvolvimento Rural Sustentável - CMDRS é o órgão gestor do desenvolvimento rural sustentável do Município de Viçosa, que terá função consultiva ou deliberativa, segundo o contexto de cada política pública ou programa de desenvolvimento rural em implementação. No meio rural, os Conselhos Municipais de Desenvolvimento Rural Sustentável (CMDRSs) foram instituídos, sobretudo, a partir de 1996, com a criação do Programa Nacional de Fortalecimento da Agricultura Familiar (Pronaf) (Brasil, 1996). Com isso, o Programa passou a estimular uma atuação dos agricultores como protagonistas das políticas públicas de desenvolvimento rural nos âmbitos de sua implementação local — gesto então inédito nos contextos brasileiros (Schneider, Silva e Marques, 2004). Em Viçosa, um dado curioso é que o CMDRS, apesar de ter seu estímulo de criação vinculado ao Pronaf, foi assumido no município como um espaço para a deliberação de quaisquer políticas de desenvolvimento rural, ganhando autonomia em relação ao próprio Pronaf. Nesse sentido, sua legislação fundadora, aprovada pela Câmara Municipal de Viçosa, considera que a gestão local das políticas públicas destinadas ao meio rural deve evidenciar, de algum modo, o CMDRS como âmbito fundamental para a gestão pública local (Viçosa, 2010). Nele, são asseguradas tanto a participação de órgãos do poder público, de representantes de entidades da sociedade civil organizada e de organizações não governamentais afins à temática, quanto, particularmente, de comunidades rurais (organizadas formalmente ou não) e de entidades representativas dos agricultores familiares e de trabalhadores assalariados rurais. Entre as atribuições do CMDRS, destaca-se a formulação do Plano Municipal de Desenvolvimento Rural Sustentável (PMDRS), instrumento que visa fundamentar o município na tomada de decisões referentes à implementação de inúmeras políticas públicas de desenvolvimento rural (tais como Política de Mecanização Agrícola; Política Municipal de Escolas Rurais; Política Municipal de Saúde Rural) protagonizadas pelas Secretarias Municipais de Viçosa, com grande destaque à Secretaria Municipal de Agropecuária e Desenvolvimento Ru- 
ral; como também as deliberações cotidianas sobre determinados aspectos implicados na implementação de algumas políticas públicas federais e estaduais (tais como Programa Nacional de Fortalecimento da Agricultura Familiar — Pronaf — , Programa Nacional de Alimentação Escolar - PNAE - e Programa de Aquisição de Alimentos - PAA), geridas, no âmbito de Viçosa, pela Empresa de Assistência Técnica e Extensão Rural do Estado de Minas Gerais (Emater-MG).

Além dessas particularidades, o CMDRS tem se configurado como cenário de experimentação de duas práticas metodológicas de suporte à participação, voltadas, sobretudo, ao fortalecimento cívico dos sujeitos rurais: a mediação dialógica e a pesquisa-ação. Com relação a isso, é possível destacar que, antes de participarem do CMDRS, vários dos representantes rurais nunca antes tinham vivenciado experiências participativas, muito menos apresentavam contato costumeiro com agentes públicos institucionais. Tal quadro anunciava um perigoso cenário de desigualdades deliberativas (Bohman, 2000; Mafra, 2012): sem saberem ao certo os limites e as possibilidades da participação em processos de desenvolvimento rural, a presença dos sujeitos rurais nas reuniões do CMDRS insinuava simplesmente o cumprimento de um protocolo dominado, em grande medida, pelos discursos institucionais. No intuito de evitar a conformação de tal cenário e vinculando-se a esforços de fortalecimento cívico e aprimoramento da participação (Mafra, 2012), as práticas metodológicas da mediação dialógica - protagonizadas pelos extensionistas da Emater — e da pesquisa-ação — protagonizadas pelo Copráticas/Grupo de Pesquisa em Comunicação, Democracia e Práticas Sociais da Universidade Federal de Viçosa (UFV), foram propostas como tentativas destinadas a qualificar democraticamente a arena formal do CMDRS.

Num levantamento documental e bibliográfico realizado sobre a utilização da pesquisa-ação e/ou da mediação dialógica como práticas metodológicas de aprimoramento da participação nos contextos dos Conselhos Gestores das Políticas Públicas, não foram encontrados trabalhos específicos. Entretanto, alguns estudos apontam a existência de aspectos fragilizadores dos processos participativos presentes em tais arenas. Sobretudo, um dos principais aspectos poderia ser atribuído a uma espécie de despreparo participativo presente na ação de conselheiros, como apontado nos estudos realizados por Teixeira (2000), Gomes (2003), Fuks, Perissionotto e Souza (2004) e Tatagiba (2002, 2005). Entre as várias conclusões apontadas por tais pesquisadores, há uma concordância em reconhecer que a inexperiência em participação política e em gestão pública, apesar de não ser, nem de longe, o único problema vinculado à participação institucionalizada, tende a dificultar o caráter deliberativo dos conselhos gestores.

No caso do meio rural, os clássicos estudos sobre os CMDRSs, protagonizados por Schneider, Silva e Marques (2004), anunciam relevantes questões. Entre elas, os autores apontam: a) uma espécie de tendência à supremacia do discurso técnico; b) a tendência da existência de processos participativos fragilizados por arranjos políticos locais, interessados a grupos hegemônicos; e c) a configuração de uma participação burocratizada, sem abertura aos discursos plurais, voltada apenas ao cumprimento dos requisitos necessários para acesso aos recursos de programas como o Pronaf. Outro dado relevante se refere aos PMDRSs: em estudo 
realizado em cinco municípios, Schneider e Silva (2004:164) apontam que tais instrumentos não foram capazes de apresentar correlações com as demandas de inúmeros contextos rurais, evidenciando-se um cenário de desarticulação das ações dos planos "enquanto partes constitutivas e potencializadoras de uma estratégia de desenvolvimento local".

Também é válido destacar que o estudo de Moura (2007) aponta para a responsabilidade de gestores públicos e organizações não governamentais no aprimoramento da participação de sujeitos rurais em arenas participativas formais, como as dos CMDRSs. E sobre a construção de processos de desenvolvimento rural que sejam participativos e dialógicos, tanto Caporal e Ramos (2006) quanto Coelho (2014) reconhecem o quanto a mediação se torna um gesto fundamental, destinado à produção de um desenvolvimento que seja feito pelas pessoas e para as pessoas. Quanto a isso, Schneider, Silva e Marques (2004) reconhecem que um dos desafios da participação no meio rural é alcançar e/ou possibilitar aos atores locais a efetividade de se fazerem representar e de direcionarem os rumos do desenvolvimento em âmbitos locais.

É possível dizer que existe um vasto campo a ser explorado no que se refere à relação entre práticas metodológicas e o aprimoramento de processos participativos, sobretudo nos contextos dos conselhos gestores voltados à participação no meio rural. E é de tal sorte que este artigo pretende examinar em que medida a utilização das práticas metodológicas da mediação dialógica e da pesquisa-ação pode potencializar a emergência da ação comunicativa em espaços participativos formais, tomando como horizonte empírico os processos participativos encetados no CMDRS de Viçosa (MG).

O trabalho se organiza em algumas partes. Inicialmente, será feita uma discussão conceitual sobre democracia deliberativa e participação em arenas formais. Tal discussão volta-se a compreender em que medida a ação comunicativa se apresenta como um tipo de interação fundamental para produção de legitimidade pública nas decisões vinculadas a processos participativos institucionalizados entre Estado e cidadãos. Em seguida, serão apresentados os procedimentos metodológicos do artigo, com destaque aos materiais pesquisados e aos métodos utilizados para o desenvolvimento do estudo em questão. Depois, será feita uma análise específica da prática metodológica da pesquisa-ação, evidenciando nuances acerca do modo como ela foi desenvolvida na arena do CMDRS de Viçosa (MG). Em seguida, será apresentada a prática metodológica da mediação dialógica (o que, para isso, será tomado um exemplo específico de mediação: a construção do PMDRS). Por fim, serão apresentadas as considerações finais do artigo, âmbito no qual serão apontados problemas, riscos e lacunas que tais práticas metodológicas possam apresentar dependendo do modo como forem propostas e desenvolvidas ainda que voltadas ao aprimoramento da participação.

\section{Democracia deliberativa e participação em arenas formais: ação comunicativa para produção de legitimidade pública}

A compreensão do cenário participativo disposto na arena do CMDRS de Viçosa se filia, inevitavelmente, a um conjunto de preocupações teórico-empíricas, voltadas a indagações acerca 
das possibilidades de implementação do ideal democrático em meio ao contexto de sociedades pós-industriais complexas e pluralistas (Habermas, 1997). Assim, a chamada virada democrática pressupõe o desenvolvimento de uma noção que ganhou considerável expressão nos cenários acadêmicos e sociais das últimas duas décadas, protagonizada, sobretudo, pela obra Direito e democracia, do intelectual alemão Jürgen Habermas: a noção de democracia deliberativa (Marques, 2009). Assim, tal concepção pressupõe uma espécie de retorno ao ideal democrático proposto pelos gregos — porém adaptado às condições atuais das sociedades contemporâneas (Vieira e Silva, 2013) —, que toma a argumentação como forma comunicativa de resolução de problemas, considerando ainda o Estado como âmbito investido de uma força pública capaz de regulamentar democraticamente as demandas sociais, nascidas sob a égide de uma proposta cidadã inclusiva e includente.

A discussão habermasiana, nesse sentido, protagoniza aquilo que podemos chamar de "virada deliberacionista" na teoria democrática (Marques, 2009), que passa a qualificar a participação dos sujeitos não apenas como algo que se relaciona à mera presença física ou a uma espécie de representatividade quantitativa de espaços e grupos. A participação é vista como um intercâmbio discursivo capaz de produzir, por meio daquilo que Habermas (1997) chama de razão comunicativa, trocas argumentativas e debates refletidos, em meio aos quais os sujeitos têm a oportunidade de reconhecer os pontos de vista um dos outros, e de se orientarem por uma espécie de ética da discussão (Marques, 2013), na qual impera a força do melhor argumento. A visada deliberacionista aposta na razão comunicativa - conformadora de um amplo processo público-reflexivo de construção de preferências e de consideração da opinião dos outros antes da tomada de decisão - como gesto capaz de expressar, ante o Estado, um poder democrático, imbuído de alta dose de legitimidade.

A democracia deliberativa busca desenvolver mecanismos voltados a qualificar a participação, o que faz com que a deliberação seja entendida como um processo social, engendrado comunicacionalmente, "que se concretiza a longo prazo através da elaboração e do uso de práticas de intercompreensão capazes de articular os diversos atores e arenas comunicativas que integram a esfera pública" (Marques, 2009:15). Além disso, tais atores devem ser estimulados a argumentar de uma forma a partir da qual o discurso produzido publicamente seja entendido e aceito pelos participantes (Cohen, 1997). Quanto a isso, Habermas (1995) faz referência a um pluralismo nas formas de se comunicar, enfatizando que a

política deliberativa somente exige uma referência empírica quando levamos em conta a pluralidade de formas de comunicação nas quais uma vontade comum pode se formar, não somente pela via de uma autocompreensão ética mas também mediante o equilíbrio de interesses e compromissos, mediante a escolha racional de meios com respeito a um fim, mediante justificações morais e exames de coerência jurídicos. (Habermas, 1995:45)

Em razão disso, sustentada pela construção da opinião e da vontade pública, a política deliberativa 
alimenta-se da constituição informal da opinião e da vontade pública. Assim, para ganhar algum tipo de eficácia política, as demandas processadas pelo debate coletivo devem ser introduzidas nas agendas parlamentares, discutidas em instâncias formais do Estado de Direito e, eventualmente, elaboradas nas formas propostas e decisões impositivas. Somente as regulamentações definidas por lei e por atos de governo têm a competência de intervir em espaços privados, transformando responsabilidades formais e práticas existentes. (Maia, 2007:105)

Dessa forma, a política deliberativa estabelece uma relação entre o poder administrativo (racionalidade do Estado) e o poder comunicativo (racionalidade que emerge do intercâmbio discursivo). Habermas (1995:43) assim sustenta que há uma diferença estrutural entre "o poder comunicativo, que surge da comunicação política na forma de opiniões majoritárias discursivamente formadas, e o poder administrativo, próprio do aparato estatal". Para o autor, a formação de opinião em uma arena discursiva apresenta como característica uma "força legitimadora" e, por conseguinte, uma "força vinculatória sobre a forma de exercer o poder político" (Habermas, 1995:43), enfatizando que, dessa forma, o poder administrativo terá validade se for pautado "com base nas políticas e nos limites das leis que surgem no processo democrático" (Habermas, 1995:43). A expressão de uma razão comunicativa, fruto de um debate público no qual se desenrola uma ação comunicativa, poderá influenciar o poder administrativo, sobretudo por sua força ética vinculatória a compromissos morais potencialmente universalizáveis.

Para Dryzek (2004:41-42), “os resultados (as decisões políticas obtidas a partir das deliberações) são legítimos na medida em que recebam o assentimento refletido por meio da participação em uma deliberação autêntica da parte de todos aqueles sujeitos à decisão em questão". Deliberação autêntica implica a qualidade do que será dialogado. A qualidade da deliberação trará um impacto positivo ou, como defendido por Bohman (2009),

o sucesso é medido não pelo forte requerimento de que todos devem concordar com os resultados, mas pelo requerimento fraco de que os interlocutores são suficientemente convincentes para continuar sua cooperação em processo. O resultado de uma decisão atual é aceitável quando as razões que o sustentam são suficientes para motivar a cooperação de todos os interlocutores. (Bohman, 2009:42)

Nesse sentido, a democracia deliberativa tem orientado a problematização acerca da qualidade da participação de inúmeros desenhos institucionais que possam acolher o debate a partir de uma participação institucionalizada. Assim, o ideal da razão comunicativa proposto por Habermas (1995) torna-se relevante para a problematização de contextos formais, como é o caso dos Conselhos Gestores de Políticas Públicas: neles, os sujeitos devem construir suas opiniões a partir de um debate público-reflexivo, voltado a produzir um poder democrático que, além de legitimar suas ações, consiga transpor inúmeras barreiras burocráticas impostas pelo Estado, fortalecendo, consequentemente, os processos de participação política. 
Dessa maneira, a qualidade da participação na arena dos Conselhos Gestores pode ser vislumbrada na medida em que se apresenta como o resultado suposto de um debate público-reflexivo estabelecido, capaz de influenciar a própria racionalidade administrativa do Estado, no que se refere a propostas oriundas da ação comunicativa (Mafra, 2011). Por isso, Habermas (1997:347) ressalta que, antes de tudo, a deliberação é "um processo de aprendizagem que se estabelece de forma reflexiva" e que se refere tanto a momentos de decisão propriamente ditos quanto a momentos de reflexão e discussão públicas.

Assumindo, dessa maneira, a deliberação como um processo de aprendizagem, e partindo da premissa de que ela nem sempre ocorre em meio aos processos participativos de inúmeras arenas formais, de acordo com evidências já apontadas na Introdução, este artigo pretende examinar se e como a utilização das práticas metodológicas da mediação dialógica e da pesquisa-ação pode potencializar a emergência da ação comunicativa em espaços participativos formais, contribuindo para a aprendizagem dos processos deliberativos. É assim que, a seguir, serão apresentados os procedimentos metodológicos voltados a descrever o modo como tais práticas foram examinadas na arena participativa do CMDRS de Viçosa.

\section{Procedimentos metodológicos}

Para atender às reflexões aqui propostas, este estudo nucleou-se em torno de duas metodologias principais: a pesquisa documental e a pesquisa qualitativa. A pesquisa documental orientou a busca e a análise dos seguintes documentos:

(i) Projeto de Pesquisa e Extensão Fortalecimento cívico e aprimoramento da participação de comunidades rurais junto ao Conselho Municipal de Desenvolvimento Rural Sustentável (CMDRS) de Viçosa/MG, protagonizado pelo Copráticas/UFV, e financiado pela Fundação de Amparo à Pesquisa do Estado de Minas Gerais (Fapemig) e pelo Ministério Público do Estado de Minas Gerais (MPMG) (Mafra, 2012); nesse documento consta a argumentação em torno do uso metodológico da pesquisa-ação como forma de aperfeiçoamento dos mecanismos participativos, por meio do estímulo à emergência da ação comunicativa; além do projeto, foram consultados relatórios e formulários de observação preenchidos pelos pesquisadores da UFV durante a realização das ações junto aos sujeitos rurais, com destaque para as dinâmicas de pesquisa-ação realizadas na arena do CMDRS durante todo o ano de 2012;

(ii) os instrumentos utilizados na metodologia Mexpar, adotada pela Emater-MG e utilizada pelos extensionistas como forma de mediação dialógica em torno da construção do Plano Municipal de Desenvolvimento Rural Sustentável (PMDRS), nas edições de 2009 e de 2013; tais instrumentos incluem um livro com a descrição da metodologia e inúmeras fichas utilizadas pelos extensionistas na construção do PDMRS;

(iii) o próprio documento final do PMDRS, produzido no âmbito do CMDRS como resultado da participação dos sujeitos inspirada pelas práticas metodológicas da pesquisa-ação (em 
2013) e da mediação dialógica (em 2009 e em 2013). Quanto a isso, é válido destacar que tal documento foi encaminhado pelo CMDRS aos poderes municipais, com fins de análise, cobrança de demandas e pressão por implementação de políticas públicas voltadas ao meio rural. O último PMDRS foi entregue no início de 2013 ao município de Viçosa (MG).

Assim, a pesquisa documental permitiu a reunião de todos esses materiais para fundamentar a análise sobre as concepções de pesquisa-ação e de mediação dialógica utilizadas como suporte à participação no CMDRS. Além disso, tais materiais, no caso do PMDRS, evidenciaram em que medida o processo de construção desse documento teve forte influência da ação comunicativa, em função das práticas metodológicas então utilizadas. A pesquisa documental teve início em maio de 2014 e foi encerrada em março de 2015.

Já a pesquisa qualitativa foi operacionalizada a partir da realização de entrevistas com 11 conselheiros do CMDRS de Viçosa, o que inclui representantes das seguintes comunidades rurais: Paula, Silêncio, Córrego do Engenho, Córrego Fundo, Córrego São Francisco, Cascalho; e das instituições: Prefeitura Municipal de Viçosa, Câmara Municipal de Viçosa; Epamig, IMA, Emater-MG. De modo peculiar, foram também entrevistados dois extensionistas da Emater-MG que trabalham envolvidos diretamente nos processos participativos do CMDRS. Adotou-se como critério de validação para seleção dos entrevistados o assento formal que os mesmos possuem no CMDRS, a saber: os conselheiros que representam a agricultura familiar (aqui denominados Representante de Comunidade Rural) e os conselheiros que representam as instituições (aqui denominados Representante Institucional). O objetivo das entrevistas voltou-se a coletar impressões, percepções e sentimentos que os entrevistados demonstraram em relação às práticas metodológicas utilizadas como suporte à participação, bem como a identificar a relação de tais percepções com a presença de indícios da ação comunicativa na arena do CMDRS. Buscamos, para a construção dos roteiros e para a realização das entrevistas, a inspiração metodológica qualitativa de Minayo (1994). As entrevistas foram realizadas no período de outubro a dezembro de 2014.

O tratamento dos dados obtidos nas entrevistas foi efetivado pela análise de conteúdo: "técnica de investigação que tem por finalidade a descrição objetiva e sistemática do conteúdo manifesto da comunicação" (Bardin, 2009:21). Essa análise foi dividida em três etapas: exploração do material, tratamento dos dados e interpretação. Depois de transcritos, os dados passaram pela chamada conferência de fidedignidade, que se procede ao ouvir a gravação tendo o texto transcrito em mãos, acompanhando e conferindo cada frase (Alberti, 1990). Após a análise, foram construídas tabelas com as respostas tal qual foram encontradas. Dando prosseguimento, as respostas foram classificadas em categorias, de acordo com a semelhança de seus conteúdos, e, por fim, a dimensão em questão foi analisada com base naquilo que se apresentou mais frequente.

Por fim, é válido ainda considerar que os dados coletados sobre a pesquisa-ação e a mediação dialógica representam momentos não totalmente coincidentes de uso de tais metodologias na arena do CMDRS: enquanto os dados da mediação dialógica se referem a ações que tiveram início em 2009 e, mais especificamente, no final de 2012 e início de 2013, com 
a construção do PMDRS, os dados da pesquisa-ação se referem a ações que foram realizadas durante todo o ano de 2012. Ainda assim, o uso dos dados se justifica uma vez que o objetivo desse estudo não foi o de examinar necessariamente um uso correlato e simultâneo das duas metodologias, mas sim o de tentar demonstrar como tais práticas metodológicas foram implementadas, de modo simultâneo ou não, e em que medida tal implementação, por si só, é capaz de insinuar traços de emergência da ação comunicativa na arena do CMDRS.

\section{Pesquisa-ação como prática metodológica para emergência da ação comunicativa}

A prática metodológica da pesquisa-ação como suporte à participação no CMDRS nasceu a partir do projeto de pesquisa e extensão Fortalecimento cívico e aprimoramento da participação de comunidades rurais junto ao Conselho Municipal de Desenvolvimento Rural Sustentável (CMDRS) de Viçosa/MG (Mafra, 2012). Vinculado aos Departamentos de Economia Rural (DER) e de Comunicação Social (DCM) da UFV, o projeto pretendeu:

promover o fortalecimento cívico e aprimorar a participação de comunidades rurais de Viçosa/ MG no Conselho Municipal de Desenvolvimento Rural Sustentável (CMDRS), a partir de processos dialógicos e participativos voltados à formação política (representação, democracia, deliberação) e temática (desenvolvimento rural sustentável) dos conselheiros e de suas comunidades rurais. (Mafra, 2012:1)

Para isso, o projeto apostou na comunicação como aspecto essencial de um aprendizado democrático voltado ao fortalecimento cívico e ao aprimoramento da participação: “é a partir do diálogo público, da inserção em meio ao dar e receber razões que os sujeitos vivenciam a oportunidade de participar de uma espécie de exercício democrático de escolha, de argumentação e de percepção do outro" (Mafra, 2012:7). E, para dar concretude a essa aposta, o projeto escolheu como prática metodológica a pesquisa-ação, conforme definida pelo pesquisador francês Michel Thiollent (2011). Nos termos do projeto:

Em linhas gerais, a pesquisa-ação fundamenta-se numa noção de pesquisa social crítica, em que o pesquisador não apenas se coloca numa relação de investigação ou de exclusivo distanciamento da realidade posta sob seus olhos. Isso porque tal metodologia sugere um conhecimento produzido a partir de uma intervenção, de uma coleta de dados acompanhada de uma ação [...] A metodologia da pesquisa-ação também sugere que é no diálogo e nas interações que as ações de pesquisa e as ações de intervenção se concretizam, modificam-se e surtem efeitos. (Mafra, 2012:14)

Assim, como propõe Thiollent (2011:16), a pesquisa-ação é um tipo de "pesquisa social concebida e realizada em estreita associação com uma ação ou com a resolução de um proble- 
ma coletivo", em meio ao qual "os pesquisadores e os participantes representativos da situação ou do problema estão envolvidos de modo cooperativo ou participativo". Nesse caso, o problema principal detectado pelo projeto referiu-se a um cenário de desigualdades deliberativas (Mafra, 2012): tendo em vista a inexperiência de inúmeros sujeitos rurais na participação em arenas formais, bem como a presença de uma tendência à supremacia de discursos técnicos, a situação-problema a ser enfrentada se apresentava como a necessidade de fazer emergir a voz dos sujeitos rurais, contemplando seus modos de expressão, suas formas argumentativas e a maneira como os mesmos julgavam relevante o encaminhamento de demandas para o debate refletido. Assim, muito antes do que uma espécie de aprendizado linear, ou mesmo de uma suposta capacitação de conselheiros, o projeto procurava, antes de tudo, incentivar situações para que os sujeitos se expressassem e pudessem ficar, em decorrência disso, à vontade para deliberar, do modo como lhes parecia mais conveniente.

Entre os quatro eixos do projeto, é possível destacar aquele em que, especificamente, dispunham-se os esforços de pesquisa-ação no âmbito do CMDRS:

[...] por meio desse eixo, pretende-se construir uma atuação específica durante as reuniões ordinárias mensais do CMDRS. A partir de pontos de pauta previamente definidos, alguns diálogos sobre a participação e sobre a temática do desenvolvimento rural sustentável serão propostos, a fim de estimular, naquele âmbito, reflexões sobre o papel do CMDRS e de cada conselheiro envolvido. Questões como regras para participação e posicionamento discursivo, ponderações sobre como tornar o espaço das reuniões mais inclusivo a partir de ações simples [...] dentre outras, buscarão formar um ambiente dialógico e participativo, propício para que o CMDRS repense sobre como tem atuado na política pública de desenvolvimento rural sustentável [...] estimulando os próprios conselheiros a se posicionarem. (Mafra, 2012:19)

Os procedimentos para execução da pesquisa-ação previam, nesse sentido, que, em cada reunião ordinária mensal do CMDRS, as equipes do projeto pudessem lançar uma pauta de reflexão previamente preparada, ocupando o espaço de até 30 minutos no início de cada reunião. Como instrumental metodológico, foi escolhida, sobretudo, a utilização de dinâmicas de grupo "com motivos lúdicos, como charges, figuras, fotos, imagens outras" que pudessem "chamar a atenção e gerar apelo ao diálogo público" (Mafra, 2012:19). As equipes do projeto, constituídas por pesquisadores de mestrado e estudantes de graduação vinculados ao Copráticas (UFV), se subdividiriam entre dois grupos: a) os responsáveis por aplicar as dinâmicas; e b) os responsáveis por registrar as impressões no momento da reunião, com foco nos conselheiros que se posicionassem e também nos que permanecessem em silêncio, tanto durante as dinâmicas quanto após o seu término, na continuidade da reunião ordinária formal.

Copráticas participou mensalmente das reuniões do CMDRS, no decorrer de 2012. Nesse período, a partir dos formulários de registro das impressões e das presenças dos conselheiros, percebeu-se no CMDRS uma participação vibrante, tanto do ponto de vista quantitativo — em que foi registrada uma média de $70 \%$ de presença dos sujeitos rurais; quanto do ponto de vista qualitativo - no qual foram observados esforços geradores de diálogo público, por 


\section{parte de tais sujeitos. Nesse período, foram, portanto, aplicadas as seguintes dinâmicas, dis- postas no quadro 1.}

\section{Dinâmicas realizadas no CMDRS}

\begin{tabular}{|c|c|c|}
\hline Mês & Dinâmica & Finalidade \\
\hline Jan. & Não houve reunião ordinária & do CMDRS \\
\hline Fev. & Liberdade de Expressão & $\begin{array}{l}\text { Os conselheiros receberam uma figura de pessoas impedidas de falar. Foi solicitado a } \\
\text { eles para dizerem o que a figura representava e, em seguida, foi proposta uma discussão } \\
\text { sobre liberdade de expressão. }\end{array}$ \\
\hline Mar. & Construtor & $\begin{array}{l}\text { Foi utilizado o brinquedo "Pequeno Construtor" (com peças em madeira) para estimular } \\
\text { os conselheiros a construírem uma casa, de modo coletivo; em seguida, foi relacionado } \\
\text { o processo de construção da casa com a ampliação democrática e as possibilidades } \\
\text { de construção coletiva que um conselho abre à sociedade. }\end{array}$ \\
\hline Abr. & $\begin{array}{l}\text { Do plantio à } \\
\text { comercialização na feira }\end{array}$ & $\begin{array}{l}\text { Foi pedido aos conselheiros que organizassem, a partir de tarjetas, o processo de } \\
\text { plantio de laranja até a sua comercialização, por exemplo, numa feira. A dinâmica foi } \\
\text { discutida relacionando-se o cumprimento de passos para a comercialização da laranja } \\
\text { com a necessidade de cumprimento de passos para a formalização de questões no } \\
\text { âmbito do CMDRS. }\end{array}$ \\
\hline Maio & Telefone sem fio & $\begin{array}{l}\text { Os conselheiros foram dispostos em duas filas e foi solicitado ao primeiro da fila que } \\
\text { passasse uma informação que precisava chegar ao último da fila (tal informação se } \\
\text { relacionava à quebra de uma ponte e à necessidade de cascalhar as estradas); o } \\
\text { último da fila deveria levar a informação, simbolicamente, ao CMDRS, da forma como } \\
\text { chegasse (a dinâmica foi mesmo inspirada na brincadeira telefone sem fio); ao final, } \\
\text { foram problematizadas questões ligadas à representação, sobretudo em relação às } \\
\text { dificuldades e aos ruídos implicados, bem como ao desafio da construção de um } \\
\text { diálogo público com aqueles que são representados. }\end{array}$ \\
\hline Jun. & Balões no ar & $\begin{array}{l}\text { Com o apoio de balões de soprar, foi pedido aos conselheiros que compusessem } \\
\text { um círculo e ficassem, cada um, de posse de apenas um balão; a proposta era que } \\
\text { o balão fosse mantido no ar, com as mãos, e que não caísse no chão. Aos poucos, } \\
\text { os conselheiros foram sendo retirados, um a um e, ao mesmo tempo, foi pedido aos } \\
\text { outros que restavam para tentar segurar todos os balões que estavam inicialmente na } \\
\text { dinâmica. Ao término da dinâmica, foi feita uma correlação do balão de soprar com } \\
\text { os problemas de cada comunidade, tentando ressaltar a importância da presença do } \\
\text { conselheiro nas reuniões para que os problemas de suas comunidades pudessem ser } \\
\text { sustentados e não caíssem no esquecimento. }\end{array}$ \\
\hline Jul. & Diagnóstico dos problemas & $\begin{array}{l}\text { Foi solicitado aos conselheiros que pensassem em 1) problemas de participação } \\
\text { no conselho, 2) sentimentos pelo fato de serem representantes e } 3 \text { ) entraves que } \\
\text { percebiam na relação com suas comunidades. Assim, foi produzida uma tabela, em } \\
\text { lousa à frente dos conselheiros, na qual foram dispostas as respostas solicitadas. O intuito } \\
\text { foi o de que os presentes pudessem visualizar os dados levantados e percebessem } \\
\text { em que medida poderiam colaborar para a mudança do cenário participativo de suas } \\
\text { comunidades. }\end{array}$ \\
\hline $\begin{array}{l}\text { Ago. } \\
\text { Set. }\end{array}$ & \multicolumn{2}{|c|}{$\begin{array}{l}\text { Não foi possível a abertura da pauta da reunião para a realização de dinâmicas. Um tempo maior foi adicionado à } \\
\text { dinâmica de outubro. }\end{array}$} \\
\hline
\end{tabular}

Continua 


\begin{tabular}{|c|c|c|}
\hline Mês & Dinâmica & Finalidade \\
\hline Out. & $\begin{array}{l}\text { Desenvolvimento } \times \\
\quad \text { Progresso }\end{array}$ & $\begin{array}{l}\text { Foi feita uma rápida problematização sobre desenvolvimento rural e sustentável, além } \\
\text { de ter sido mencionada a diferença entre progresso e sustentabilidade. No local, foi } \\
\text { escolhida uma parede, de modo que os conselheiros, em círculo, se posicionaram } \\
\text { de frente para ela; após dividir tal parede ao meio, foram afixadas, por meio de duas } \\
\text { tarjetas, de um lado, a palavra progresso e, de outro, a palavra desenvolvimento; foram } \\
\text { espalhadas, ao chão, diversas figuras (como fotos de irrigação, uso de agrotóxicos, } \\
\text { trânsito caótico, telhado verde, telefonia celular, torneira com água pingando, energia } \\
\text { eólica etc.) e foi solicitado aos conselheiros que: 1) diante das imagens, cada um } \\
\text { deles, de modo subsequente, escolhesse uma imagem para fixar em um dos lados, } \\
\text { justificando suas escolhas de acordo com os seus conhecimentos sobre a temática } \\
\text { da dinâmica; 2) após a fixação das imagens na parede e após a justificativa emitida } \\
\text { publicamente pelos conselheiros, foi feita uma reflexão sobre as imagens e as } \\
\text { tarjetas da dinâmica, em relação ao conceito de sustentabilidade e ao trabalho do } \\
\text { CMDRS; após a reflexão, os conselheiros poderiam alterar o local em que fixaram } \\
\text { inicialmente suas imagens ou também deixá-las onde inicialmente as afixaram; a } \\
\text { conclusão da dinâmica girou em torno da ideia de que a origem do Conselho se } \\
\text { deu justamente em torno do que foi tratado durante a atividade: a busca por uma } \\
\text { visão de desenvolvimento não baseada em progresso e em crescimento, mas numa } \\
\text { proposta nova de sustentabilidade. }\end{array}$ \\
\hline Nov. & \multicolumn{2}{|c|}{$\begin{array}{l}\text { Não houve dinâmica. Mês em que foi realizado um Seminário Específico de Formação Política, destinado aos } \\
\text { conselheiros do CMDRS. }\end{array}$} \\
\hline Dez. & \multicolumn{2}{|c|}{$\begin{array}{l}\text { Foi pedido aos integrantes do CMDRS (conselheiros, instituições e demais participantes) que avaliassem a participação } \\
\text { das equipes do Copráticas no âmbito do conselho. A avaliação foi positiva: em algumas respostas, houve sinalizações } \\
\text { acerca de um considerável fortalecimento político, sobretudo com o desenvolvimento das dinâmicas e do curso de } \\
\text { formação política. Além disso, foi feita uma espécie de celebração do ano de } 2012 \text {, com uma apresentação em Power } \\
\text { Point com algumas fotos sobre a trajetória de atuação das equipes junto ao CMDRS, desde fevereiro. }\end{array}$} \\
\hline
\end{tabular}

Fonte: Adaptação dos relatórios do Projeto Fortalecimento Cívico, 2012.

Levando-se em conta a observação de Habermas (1995) quanto à necessária pluralidade de formas de comunicação em processos de deliberação pública, é válido dizer que os momentos das dinâmicas acolhiam formas de comunicação múltiplas e, ao mesmo tempo, buscavam convocar os conselheiros a proferirem justificações morais acerca de suas posições, uns em relação aos outros. Por tudo isso, pode-se dizer que as dinâmicas se destinavam não apenas aos sujeitos rurais, mas também aos representantes institucionais. O exercício dialógico decorrente dessa prática constrangia positivamente, nesse sentido, os representantes institucionais a expressarem seus posicionamentos com base em justificações morais, como também os sujeitos rurais a apreenderem particularidades e inúmeras nuances burocráticas implicadas nos processos de gestão pública.

Em entrevistas realizadas com os conselheiros, é interessante perceber como a deliberação, como processo de aprendizado social, emergiu na arena do CMDRS. Em referência específica à primeira dinâmica realizada pelo Copráticas (Liberdade de Expressão), dois relatos traduzem e revelam a importância desse momento: 
Foi a partir das dinâmicas dele foi que eu tomei coragem e comecei a falar. Então eu aprendi, ele abriu a minha boca e acho que num vai fechar mais não. (Representante de Comunidade Rural) (grifo nosso)

Reforçou muito o CMDR porque botou a gente pra falar. A gente num falava, né [conselheira]. Tirou aquele fecho da nossa boca, que nóis, que ele apresentou na primeira dinâmica dele. Então ele incentivou a gente a dá mais palpite, mais sugestões da, comé que fala, interagir mesmo com o CMDR que a gente ia lá ficava escutando, intendia nada, vortava pra casa. (Representante de Comunidade Rural) (grifo nosso)

O segundo depoimento não retrata, especificamente, nenhuma dinâmica em particular. Os entrevistados sinalizam o grande valor que foi atribuído à prática metodológica da pesquisa-ação:

Num vão dizer assim que eu melhorei, mas todos, viu. Todos gostam, todos participam, todos acha maravilhoso do jeito que [o projeto faz] todo mundo participar, entendeu. Todo mundo, num fica calado. Cê vê que tem hora ali que parece uma caixa de abelha, todo mundo qué falá ao mesmo tempo. (Representante de Comunidade Rural) (grifo nosso)

Aí depois do professor pegou a frequentar nossa reunião, dois anos já né, aí que a gente se abriu mais, ele pegou mais de gestão, pegou fazer aquelas dinâmica lá né. Eu adorava aquelas dinâmicas. (Representante de Comunidade Rural) (grifo nosso)

A segurança que os conselheiros sentiam ao manifestar sua opinião e ao discutir, por meio do debate, quando não concordavam com alguma questão também foi percebida pelos conselheiros representantes das instituições:

A gente vê claramente a mudança, né. Até mesmo pra eles porem o problema deles, que muitos ficavam calados e não falavam. Eles agora falam! Eles agora falam, já tem liberdade com toda a equipe né, eles já falam, muitas vezes não precisa nem perguntar, eles já chegam lá com os questionamentos. (Representante Institucional)

Extremamente fundamental. É, [...], igual eu te falei, tem o lado do produtor né, que é o lado simples do produtor não saber se posicionar muitas vezes e, toda aquela dinâmica que é feita com professor, todo aqueles trabalhos que são executados por vocês lá dentro do Conselho dá abertura pro produtor dele se comunicar. (Representante Institucional)

Eu acho que as rédeas do Conselho tem que ser realmente da comunidade, das comunidades que tão sendo representadas lá. Então assim, o trabalho do professor eu achei muito interessante porque ele guiava. É diferente de você comandar. (Representante Institucional) 
A análise dos dados indica uma forte tendência ao fortalecimento dialógico desses conselheiros, pois demonstra que o lugar de comunicação deles foi, de algum modo, alterado. A liberdade com que demonstravam se sentirem mais preparados para falar e as cobranças por justificações dirigidas na arena do CMDRS são fortes indícios da presença da ação comunicativa em meio à participação institucionalizada. O estímulo à fala dos sujeitos rurais, no sentido de argumentarem sobre suas vidas, suas experiências e expectativas de mundo, se mostrou como elemento essencial para constituírem um potencial de emergência à ação comunicativa e de aprendizado social sobre deliberação pública, no âmbito participativo do CMDRS.

\section{Mediação dialógica como prática metodológica de extensão rural para emergência da ação comunicativa}

A mediação dialógica como prática metodológica utilizada no contexto do CMDRS pelos extensionistas da Emater-MG remonta ao ano de 2009, quando, naquele contexto, levantou-se a necessidade de cumprimento da demanda legal de construção do PMDRS de Viçosa (MG). Ocupando a Emater-MG a cadeira de Secretaria Executiva do CMDRS, e imbuída da função de construir relações com o meio rural pautadas pelo diálogo, a mediação dialógica apareceu como possibilidade destinada aos extensionistas rurais de oferecerem um suporte à participação dos conselheiros - sobretudo no sentido de construir um documento que correspondesse legitimamente aos anseios e às inúmeras demandas por políticas públicas de sujeitos habitantes do meio rural.

Quanto a esse esforço, é válido considerar que os extensionistas em questão pautaramse por uma proposta de Assistência Técnica e Extensão Rural (Ater), dedicada à mediação de saberes e conhecimentos, em meio à qual o extensionista rural torna-se "um agente impulsionador do desenvolvimento das comunidades rurais, que influi também nas mudanças institucionais que são necessárias nas entidades de Ater" (Caporal e Ramos, 2006:6). A mediação, para esses autores, deve propor ações educativas, democráticas e participativas, afastando-se de uma proposta metodológica na qual o caráter difusionista, a racionalidade burocrática e o saber técnico-científico, segundo Marques (2009), outorgam aos técnicos de extensão rural uma forte legitimidade. A representação do grupo profissional dos extensionistas rurais, marcada pela ênfase no papel da técnica sobre as relações dialógicas, tende a conformar, portanto, uma posição submissa dos agricultores, construída sobre a autoimagem de uma suposta incompetência para intervir nas políticas participativas de desenvolvimento local.

A visão de uma mediação dialógica encontra profunda consonância no que foi proposto pela Política Nacional de Assistência Técnica e Extensão Rural (Pnater). De acordo com essa lei, "a Extensão Rural pública deve priorizar a relação entre agricultores e agentes de ATER, criando novas possibilidades de resgate dos conhecimentos locais e de participação consciente nas mudanças necessárias nos níveis político, social, ambiental, econômico, cultural e ético" (Caporal e Ramos, 2006:6). Nesse ínterim, são recomendadas ao extensionista a adoção de estratégias coletivas e a admissão de um caráter, além do técnico, de "mediador e facilitador 
de processos de desenvolvimento, dando-se conta de que atua numa realidade concreta da qual faz parte e sobre a qual tem influência" (Caporal e Ramos, 2006:10).

Inspirados por essa proposta, os extensionistas da Emater pautaram a construção do PMDRS, tanto em 2009 quanto em 2013, a partir do atendimento a duas etapas fundamentais: a primeira buscou conhecer a realidade das comunidades rurais, por meio da Metodologia Participativa de Extensão Rural para o Desenvolvimento Sustentável (Mexpar); e na segunda etapa foram realizados Seminários de Avaliação das Demandas levantadas nas comunidades, agora na arena formal do CMDRS, com o intuito de priorizar as ações que seriam dispostas no PMDRS.

Com relação à primeira etapa, é válido destacar que a Mexpar tem como foco os princípios "da dialogicidade e troca de saberes, do planejamento participativo e da gestão social, capaz de orientar a sua prática junto aos agricultores familiares e outros atores sociais na implementação de estratégias de desenvolvimento rural sustentável" (Ruas, 2006:12). Tal metodologia foi uma iniciativa da Emater-MG elaborada às luzes do construtivismo de Jean Piaget e do método pedagógico de Paulo Freire. Para nortear a mediação dos extensionistas, a Mexpar propõe três momentos: o conhecimento da realidade; a organização da ação e gestão social; e a execução da ação e acompanhamento.

Quanto a isso, é válido apontar que as técnicas indicadas na metodologia para a coleta de dados são as mesmas indicadas no Diagnóstico Rural Participativo (DRP) e apresentam como princípio básico "o entendimento da participação como processo e, portanto, em construção permanente do seu significado na prática social” (Ruas, 2006:55). Importante destacar que todos os extensionistas passaram por uma capacitação antes de adotarem essa metodologia, com especial ênfase na participação e no construtivismo, como aponta depoimento de um extensionista da Emater/MG:

a Emater tem, é assim, nos capacitou pra gente trabalhar metodologia participativa e, principalmente, construtivismo. Sabe, a gente construir o entendimento com tudo que for fazer, pra usar o método de construção, tá. (Extensionista Rural 1)

No que se refere ao DRP, importa destacar que Coelho (2014) chama a atenção para que suas metodologias não sejam aplicadas de modo automático. Devem, ao contrário, ser adaptadas pelos extensionistas, buscando sempre adequar o processo ao contexto e avaliar, constantemente, as experiências relacionadas àqueles que a vivenciam, de modo a melhor apreender os efeitos das posturas, das atividades e das dinâmicas de grupo. Caporal e Ramos (2006:12), por sua vez, corroboram Coelho (2014) ao concordarem que essas metodologias não devem ser usadas de forma mecânica, já que o DRP corresponde "a um compromisso com uma ação de caráter democrático, que permita a leitura da realidade pelos grupos de agricultores e pelos técnicos envolvidos, de modo que as decisões sobre o futuro dos coletivos possam ser tomadas de forma consciente".

Tendo como uso a Mexpar (portanto, uma manifestação específica de um tipo de DRP) e orientados a conhecer e a entender a realidade dos sujeitos rurais de Viçosa, os extensionis- 
tas da Emater optaram pela técnica prevista na metodologia do "Painel de Visualização", voltada, sobretudo, a identificar e a expressar, a todos os presentes no momento de aplicação da técnica, as principais demandas de cada comunidade. Essa etapa aconteceu no ano de 2009 e foi realizada com base em duas visitas em cada comunidade, totalizando 30 visitas. Assim que as demandas surgiam, eram anotadas e separadas em tarjetas de cores diferenciadas, facilitando, dessa forma, a identificação imediata do problema diagnosticado pelos agricultores. Em seguida, tais tarjetas eram fixadas num painel à frente dos presentes para que o mesmo pudesse ser visualizado por todos. Os fragmentos transcritos a seguir, referentes às falas dos sujeitos rurais presentes, revelam que a técnica escolhida para o diagnóstico teve um impacto positivo junto aos agricultores:

Foi muito legal! Então, o esquema que a Emater traço é de, a gente fez um círculo e aí, elas perguntavam qual que é as necessidades que a gente tem aqui na Paula. Acho que a primeira é estrada. Aí ela colocava na plaquinha e colocando num painel que ela colocou lá no chão, que era muita coisa. E assim foi colocando todas as necessidades que a gente viu que tinha. (Representante de Comunidade Rural 1)

[a extensionista] levantou todos os problemas e, depois elegeu o que era mais prioridade e foi mais pela escolha do povo. [...] Gostamo. Foi muito bom. A forma como é feito num precisa fazer melhor não. Precisa mudar não que é muito bem feito. (Representante de Comunidade Rural 2)

Foi levado a fichinha e cada comunidade escrevia na fichinha o que mais tava precisando. Cada pessoa, né? Foi bastante gente. Então cada um ficava a vontade pra escrever na fichinha o que achava que tava sendo, precisando na comunidade. Então as pessoas foram só escrevendo na fichinha e foi colando no quadro. (Representante de Comunidade Rural 5)

Aí cada um falava uma coisa. Tá precisando disso, disso, disso. Aí [a extensionista rural] punha lá, ia anotano nas ficha lá. Igual essas ficha que ocês leva lá. Aí que ela começou a junta aí pra formar esse Prano lá. Quê que cês tá faltano aqui na roça, pras suas comunidade? Aí um falava, tá faltando uma coisa. Tá fartano escola! Tá fartano médico! Fartano estrada! Fartano ponte! Tá fartano isso! Aí ela foi pono, foi pono. (Representante de Comunidade Rural 7)

Na sequência, a segunda etapa voltou-se para a elaboração do próprio PDMRS no momento chamado "Seminários de Avaliação". Acontecidos durante as reuniões mensais do CMDRS, durante o ano de 2010, foram totalizados nove seminários. Nesses encontros, as demandas eram discutidas exaustivamente com os conselheiros e, novamente, foi feito um levantamento para que se pudesse ter a certeza de quais problemas eram compartilhados por todos, ou se seria necessário especificar a comunidade em especial que demandava soluções para um determinado problema - afinal de contas, o PMDRS não se refere a uma comunidade em específico, mas ao meio rural como um todo. 
O próximo passo foi correlacionar as demandas encontradas em três dimensões, quais sejam: (i) a Dimensão Econômica, na qual se encontram as ações econômicas para o desenvolvimento rural; (ii) a Dimensão Ambiental, voltada às ações para o desenvolvimento sustentável; e (iii) a Dimensão Sociocultural, que corresponde à infraestrutura das comunidades, compreendendo ações para as áreas de saúde, educação, segurança, transporte e lazer.

Em 2013, o PMDRS construído em 2010 passou por uma avaliação com o intuito de verificar quais ações já haviam se realizado. Nesse momento, os extensionistas da Emater reaplicaram a Mexpar, com o Painel de Visualização, e com os Seminários de Avaliação. Entretanto, não houve reuniões nas comunidades: foram recuperadas todas as fichas das reuniões realizadas nas comunidades em 2010 e repassadas somente na arena do CMDRS. As demandas foram debatidas, uma a uma, com todos os conselheiros, representantes das comunidades rurais e das instituições, e o intuito foi o de verificar em que medida tais demandas já tinham sido atendidas, ou em que medida elas ainda se mostravam atuais.

Depois da realização de quatro Seminários de Avaliação do PDMRS, no ano de 2013, um documento com as demandas foi consolidado por equipe escolhida entre os próprios conselheiros, responsável pela adequação das ideias, pela análise e pela formalização de uma justificativa que advertisse sobre a legitimidade do processo de construção do PMDRS. A equipe foi constituída pelos extensionistas da Emater-MG e por integrantes do Copráticas.

De tal sorte, pode-se entender que o processo de constituição do PMDRS se apresentou como um dos resultados da ação comunicativa estimulada pela prática metodológica da mediação dialógica. As ações nele descritas foram oriundas de um amplo e complexo debate público-reflexivo, com vistas à institucionalização de um poder comunicativo capaz de aumentar as chances de produzir decisões mais justas e legítimas. A mediação dialógica, nesse sentido, inspirou a produção de um documento - o PMDRS — construído por uma espécie de "linguagem administrativa", mas igualmente construído por uma força legitimadora, nascida de inúmeros intercâmbios discursivos permitidos pela participação dos sujeitos, sobretudo na arena do CMDRS. Uma análise mais específica sobre outros aspectos relativos à construção do PMDRS no âmbito do CMDRS de Viçosa pode ser encontrada em Mucci (2015). O trabalho buscou problematizar em que medida um processo de planejamento de uma política pública de desenvolvimento rural, construído de modo participativo numa arena democrática formal, é capaz de gerar efeitos de fortalecimento dos meios de vida dos sujeitos rurais. Assim, a pesquisa proposta por Mucci (2015) transcende a análise das práticas metodológicas e se volta a outros aspectos implicados na construção do PMDRS de maneira mais ampla.

\section{Considerações finais}

O objetivo deste trabalho foi o de ponderar em que medida a pesquisa-ação e a mediação dialógica podem ser utilizadas como práticas metodológicas para emergência da ação comunicativa em Conselhos Gestores de Políticas Públicas - tomando como realidade específica a arena do Conselho Municipal de Desenvolvimento Rural Sustentável de Viçosa-MG (CM- 
DRS). Para atender ao objetivo proposto, optou-se por uma combinação metodológica entre pesquisa documental e pesquisa qualitativa na tentativa de buscar sinais contundentes que evidenciassem a emergência da ação comunicativa em tal âmbito de participação política de sujeitos rurais.

Com relação ao uso de tais práticas metodológicas, é preciso, no espaço dessas considerações finais, apontar dois sérios riscos que podem ser vislumbrados. O primeiro deles indica que as práticas metodológicas aqui elencadas foram protagonizadas por duas instituições que possuem assento no CMDRS: a UFV e a Emater-MG. Torna-se prudente ponderar que, se há, em alguma medida, o protagonismo de tais instituições na condução das práticas metodológicas em questão, há, por sua vez, a tendência de que os sujeitos sempre se posicionem com referência ao que tais instituições pautam como o melhor. Ao contrário disso, o que se deve esperar, em última análise, é que a referência seja feita à comunidade e que os sujeitos rurais partilhem do entendimento de que as reflexões e os debates que acontecem durante as reuniões devem ser compartilhados com os outros moradores dos espaços que eles representam.

Um segundo risco que pode ser vislumbrado encontra-se presente na tendência ao não questionamento das próprias práticas metodológicas utilizadas. Além de as mesmas não se apresentarem como as únicas que podem oferecer um suporte aos processos participativos, outras metodologias, por exemplo, que estimulem a organização social do representante, da sua comunidade ou da sua instituição devem também ser cogitadas. Vale ressaltar que, se apenas essas duas práticas metodológicas forem sempre generalizadas, incorre-se o risco de uma espécie de colonização dos espaços participativos por parte das instituições que as protagonizam. Ainda que sejam carregadas de boas intenções, tais práticas podem acabar por cercear esses espaços participativos, impedindo, em última análise, que os próprios sujeitos tomem as rédeas da participação e da deliberação.

Por fim, infere-se que é preciso que sejam desenvolvidos mais estudos, por exemplo, sobre o PMDRS, pensando em que medida a ação comunicativa fortaleceu os sujeitos rurais durante a elaboração do Plano e, posteriormente, se esse poder comunicativo foi capaz de enfrentar o poder administrativo, no que se refere à execução das ações nele contidas. São, portanto, searas instigantes de estudos, ávidas por serem problematizadas e pesquisadas.

\section{Referências}

ALBERTI, Verena. História oral: a experiência do CPDOC. Rio de Janeiro: Fundação Getulio Vargas, 1990.

BARDIN, Laurence. Análise de conteúdo. 5. ed. Lisboa: Edições 70, 2009.

BOHMAN, James. O que é deliberação pública? Uma abordagem dialógica. In: MARQUES, Angela (Org.). A deliberação pública e suas dimensões políticas e comunicativas: textos fundamentais. Belo Horizonte: Autêntica, 2009. 
BOHMAN, James. Public deliberation: pluralism, complexity and democracy. Cambridge: MIT Press, 2000.

BRASIL. Ministério do Desenvolvimento Agrário. Programa Nacional de Fortalecimento da Agricultura Familiar. Brasília, DF: SAF; Pronaf, 1996.

CAPORAL, Francisco R.; RAMOS, Ladjane de F. Da extensão rural convencional à extensão rural para o desenvolvimento sustentável: enfrentar desafios para romper a inércia. 2006. Disponível em: <www.pronaf.gov.br/dater>. Acesso em: 22 abr. 2012.

COELHO, France M. G. A arte das orientações técnicas no campo: concepções e métodos. 2. ed. rev. ampl. Viçosa, MG: Suprema, 2014.

COHEN, Joshua. Deliberation and democractic legitimacy. In: BOHMAN, John; REGH, William (Org.). Deliberative democracy. Cambridge, Mass.: MIT Press, 1997. p. 67-91.

DRYZEK, John S. Legitimidade e economia na democracia deliberativa. In: COELHO, Vera S. P.; NOBRE, Marcos (Org.). Participação e deliberação: teoria democrática e experiências institucionais no Brasil contemporâneo. São Paulo: Editora 34, 2004. p. 21-41.

FREIRE, Paulo. Extensão ou comunicação? 15. ed. São Paulo: Paz e Terra, 2011.

FUKS, Mario; PERISSINOTTO, Renato M.; SOUZA, Nelson R. de (Org.). Democracia e participação: os conselhos gestores do Paraná. Curitiba: Ed. UFPR, 2004.

GOMES, Eduardo G. M. Conselhos Gestores de Políticas Públicas: democracia, controle social e instituições. Dissertação (mestrado em administração pública e governo) — Escola de Administração de Empresas, Fundação Getulio Vargas, São Paulo, 2003.

HABERMAS, Jürgen. Direito e democracia: entre faticidade e validade. Rio de Janeiro: Tempo Brasileiro, 1997.

HABERMAS, Jürgen. Teoría de la acción comunicativa II: crítica de la razón funcionalista. Madri: Taurus, 1987.

HABERMAS, Jürgen. Três modelos normativos de democracia. Lua Nova, São Paulo, n. 36, p. 3953, 1995.

MAFRA, Rennan L. M. Deliberação mediada e legitimidade discursiva: uma aproximação possível? Cadernos da Escola do Legislativo, Belo Horizonte, v. 13, n. 20, p. 61-82, jan./jun. 2011.

MAFRA, Rennan L. M. Fortalecimento cívico e aprimoramento da participação de comunidades rurais junto ao Conselho Municipal de Desenvolvimento Rural Sustentável (CMDRS) de Viçosa/MG. Projeto de Pesquisa. Viçosa; Belo Horizonte: Fapemig, 2012.

MAIA, Rousiley C. M. Política deliberativa e tipologia de esfera pública. BIB. Revista Brasileira de Informação Bibliográfica em Ciências Sociais, v. 63, p. 91-116, 2007.

MARQUES, Angela. A ética do discurso e a formação do sujeito político em Habermas. Cadernos da Escola do Legislativo, v. 5, n. 23, p. 161-183, jan./jun. 2013. 
MARQUES, Angela (Org.). A deliberação pública e suas dimensões políticas e comunicativas: textos fundamentais. Belo Horizonte: Autêntica, 2009.

MARQUES, Paulo E. M. Participação e Pronaf: um estudo do poder, dos atores e dos conflitos em torno dos conselhos municipais de desenvolvimento rural. In: SCHNEIDER, Sergio; SILVA, Marcelo Kunrath; MARQUES, Paulo Eduardo M. (Org.). Políticas públicas e participação social no Brasil rural. Porto Alegre: Ed. da UFRGS, 2004. p. 21-50.

MINAYO, Maria Cecília de S. O desafio do conhecimento: pesquisa qualitativa em saúde. São Paulo: Hucitec, 1994.

MOURA, Joana T. V. de. Os Conselhos Municipais de Desenvolvimento Rural (CMDRS) e a construção democrática: esfera pública de debate entre agricultores familiares e o estado? Organizações Rurais \& Agroindustriais, Lavras, v. 9, n. 2, p. 241-255, 2007.

MUCCI, Carla Beatriz M. R. Tá achando que aqui só tem bobim da roça? Meios de vida e participação de sujeitos rurais na elaboração de um plano municipal de desenvolvimento rural sustentável. Dissertação (mestrado) — Universidade Federal de Viçosa, Viçosa, 2015.

RUAS, Elma D. Metodologia Participativa de Extensão Rural para o Desenvolvimento Sustentável Mexpar. Belo Horizonte: Emater-MG, 2006.

SCHNEIDER, Sérgio; MATTEI, Lauro; CAZELLA, Ademir Antônio. Histórico, caracterização e dinâmica recente do Pronaf - Programa Nacional de Fortalecimento da Agricultura Familiar. In: SCHNEIDER, Sergio; SILVA, Marcelo K.; MARQUES, Paulo Eduardo M. (Org.). Políticas públicas e participação social no Brasil rural. Porto Alegre: Ed. da UFRGS, 2004. p. 21-50.

SCHNEIDER, Sérgio; SILVA, Marcelo K. A participação dos agricultores nas políticas de desenvolvimento rural: uma análise do Pronaf Infraestrutura e Serviços no estado do Rio Grande do Sul. In: SCHNEIDER, Sergio; SILVA, Marcelo K.; MARQUES, Paulo Eduardo M. (Org.). Políticas públicas e participação social no Brasil rural. Porto Alegre: Ed. da UFRGS, 2004. p. 147-174.

SCHNEIDER, Sergio; SILVA, Marcelo K.; MARQUES, Paulo E. M. Políticas públicas e participação social no Brasil rural. Porto Alegre: Ed. da UFRGS, 2004.

TATAGIBA, Luciana. Conselhos gestores de políticas públicas e democracia participativa: aprofundando o debate. Rev. Sociol. Polít., Curitiba, v. 25, p. 209-213, nov. 2005.

TATAGIBA, Luciana. Os conselhos gestores e a democratização das políticas públicas no Brasil. In: DAGNINO, Evelina. Sociedade civil e espaços públicos no Brasil. São Paulo: Paz e Terra, 2002.

TEIXEIRA, Elenaldo C. Conselhos de políticas públicas: efetivamente uma nova institucionalidade participativa? In: CARVALHO, Maria do Carmo A. A.; TEIXEIRA, Ana Cláudia C. (Org.). Conselhos gestores de políticas públicas. São Paulo: Polis, 2000. (Publicações Polis n. 37).

THIOLLENT, Michel. Metodologia da pesquisa-ação. 18. ed. São Paulo: Cortez, 2011.

VIÇOSA. Lei no 2.081 de 18 de novembro de 2010. Dispõe sobre a reformulação do Conselho Municipal de Desenvolvimento Rural Sustentável — CMDRS e dá outras providências. Disponível em: <www.camaravicosa.mg.gov.br> Acesso em: 10 maio 2012. 
VIÇOSA. Lei no 2.137 de 16 de maio de 2011. Acrescenta alíneas nos incisos I e II do artigo 6o da Lei no $2.081 / 2010$, que dispõe sobre a reformulação do Conselho Municipal de Desenvolvimento Rural Sustentável — CMDRS e dá outras providências. Disponível em: <www.camaravicosa.mg.gov.br> . Acesso em: 10 maio 2012.

VIEIRA, Mônica; SILVA, Filipe. Democracia deliberativa hoje: desafios e perspectivas. Revista Brasileira de Ciência Política, n. 10, p. 151-194, jan./abr. 2013.

Carla Beatriz Marques Rocha e Mucci é mestre em extensão rural e pesquisadora pela Universidade Federal de Viçosa (UFV). E-mail: carla.beatriz@ufv.br.

Rennan Lanna Martins Mafra é doutor em comunicação social, professor adjunto do Departamento de Comunicação Social da Universidade Federal de Viçosa (UFV) e líder do Copráticas — Grupo de Pesquisa em Comunicação, Democracia e Práticas Sociais. E-mail: rennan.mafra@ufv.br. 